\title{
Detection of Mammalian microRNA Expression by In Situ Hybridization With RNA Oligonucleotides
}

\author{
Monika Deo, ${ }^{1}$ Jenn-Yah Yu, ${ }^{1,2 \dagger}$ Kwan-Ho Chung, ${ }^{1,2}$ Melissa Tippens, ${ }^{1}$ and David L. Turner ${ }^{1-3 *}$
}

We have developed an in situ hybridization procedure for the detection of microRNAs (miRNAs) in tissue sections from mouse embryos and adult organs. The method uses highly specific washing conditions for RNA oligonucleotide probes conjugated to a fluorescein hapten. We show that this method detects predominantly mature miRNAs rather than the miRNA precursors or primary transcripts. We have determined expression patterns for several miRNAs expressed in the developing and adult nervous system, including miR-124a, miR-9, miR-92, and miR-204. Whereas miR-124a is expressed in neurons, miR-9 is expressed in neural progenitors and some neurons, and miR-204 is expressed in the choroid plexus, retinal pigment epithelium, and ciliary body. miR-204 is located in an intron of the TRPM3 gene, and the TRPM3 mRNA is coexpressed with miR-204 in the choroid plexus. We also find that primary transcripts for miR-124a and miR-9 genes are expressed in patterns similar to their respective mature miRNAs. The ability to visualize expression of specific miRNAs in embryos and tissues should aid studies on miRNA function. Developmental Dynamics 235:2538-2548, 2006. ๑ 2006 Wiley-Liss, Inc.

Key words: microRNA; in situ hybridization; brain; choroid plexus; retina

Accepted 14 April 2006

\section{INTRODUCTION}

During the past several years, hundreds of genes for small noncoding RNAs known as microRNAs (miRNAs) have been identified in mammals and other animals (Lagos-Quintana et al., 2001, 2002; Lau et al., 2001; Lee and Ambros, 2001; Mourelatos et al., 2002; Dostie et al., 2003; Lim et al., 2003a; Bentwich et al., 2005; Berezikov et al., 2005; Sewer et al., 2005; Xie et al., 2005). miRNAs are typically 20-24 nucleotides (nt) in length and mediate sequence-specific binding of a protein-miRNA complex to partially or completely complementary sequences in target mRNAs. The protein-miRNA complex then negatively regulates gene expression at the level of mRNA stability and/or translation (Yekta et al., 2004; Bagga et al., 2005; Liu et al., 2005; Petersen et al., 2006). The synthesis of miRNAs is a multiple-step process. Initially, miRNAs are transcribed by RNA polymerase II as long primary transcripts (primiRNAs) that are cleaved by the Drosha endonuclease to release approximately 60-nt stem-loop precursors (pre-miRNAs; Lee et al., 2003;
Gregory et al., 2004; Zeng et al., 2005). The stem-loop precursor is exported from the nucleus and processed by the Dicer endonuclease to release the mature miRNA so that it can be incorporated into a complex with a member of the Argonaute protein family (Hutvagner et al., 2001; Ketting et al., 2001; Lee et al., 2002; Mourelatos et al., 2002; Meister et al., 2004).

Tissue-specific cloning, Northern blot, and microarray analyses have revealed that most mammalian miRNAs are expressed in specific tissues (Lagos-Quintana et al., 2002, 2003;

${ }^{1}$ Molecular and Behavioral Neuroscience Institute, University of Michigan, Ann Arbor, Michigan

${ }^{2}$ Program in Neuroscience, University of Michigan, Ann Arbor, Michigan

${ }^{3}$ Department of Biological Chemistry, University of Michigan, Ann Arbor, Michigan

†J.-H. Yu's present address is Department of Biochemistry, University of Washington, Seattle, WA 98195.

*Correspondence to: David L. Turner, Molecular and Behavioral Neuroscience Institute, University of Michigan, 5062 BSRB, 109 Zina Pitcher Place, Ann Arbor, MI 48109-2200. E-mail: dlturner@umich.edu

DOI 10.1002/dvdy.20847

Published online 30 May 2006 in Wiley InterScience (www.interscience.wiley.com). 
Dostie et al., 2003; Krichevsky et al., 2003). Strikingly, many miRNAs are expressed preferentially or exclusively in developing and/or adult nervous system, suggesting that miRNA regulation may play a large role in mammalian neurogenesis or neuronal function. Functional analyses have identified miRNAs that regulate neuronal cell fate and differentiation in invertebrates (Johnston et al., 2005), and recent studies have suggested roles for several miRNAs in mammalian neuronal differentiation (Krichevsky et al., 2005; Vo et al., 2005; Wu and Belasco, 2005).

One limitation on analysis of miRNA functions in the mammalian nervous system has been the difficulty in determining the expression patterns for specific miRNAs. Most studies have determined miRNA expression by analysis of RNA isolated from dissected tissue, an approach with limited spatial resolution. An alternative, used in both invertebrates and vertebrates, has been to introduce a genetically encoded sensor molecule that is expressed widely but inhibited in cells in which a specific miRNA is present (Brennecke et al., 2003; Mansfield et al., 2004; Smirnova et al., 2005). Although powerful, this method requires transgenic animals to visualize expression in vivo. Recently, it has been reported that nonradioactive in situ hybridization with locked nucleic acid (LNA) probes labeled with a digoxigenin hapten can be used to detect miRNAs (Sokol and Ambros, 2005; Wienholds et al., 2005; Kloosterman et al., 2006; Nelson et al., 2006). We have independently developed an in situ hybridization method for miRNA detection based on RNA oligonucleotide probes linked to a fluorescein hapten. Here, we show that this method can be used to directly detect mature miRNAs in tissue sections from developing mouse embryos, adult brain, and eye.

\section{RESULTS}

Conventional nonradioactive in situ hybridization uses synthetic RNA probes complementary to a region of an mRNA from several hundred to several thousand nucleotides in length, with a hapten present approximately every $25 \mathrm{nt}$ on the probe, and probes are detected with antibody to the hapten. Although mature miRNAs are only approximately $22 \mathrm{nt}$ in length, they are much more abundant than mRNAs (Lim et al., 2003b), which suggested to us that an oligonucleotide probe with a single hapten could bind to a sufficient number of copies of a specific miRNA to compensate for the reduced number of haptens per probe. Highly stringent wash conditions have been developed for the detection of mismatches in DNA after hybridization with labeled DNA oligonucleotide probes, based on the use of tetramethyl ammonium chloride (TMAC) to make the melting temperature $(\mathrm{Tm})$ of the oligonucleotide and its target a function of duplex length, independent of GC content (Wood et al., 1985; Jacobs et al., 1988; Litt et al., 1998). TMAC also reduces the melting temperature of an RNA:RNA duplex to that of an equivalent DNA: DNA duplex (Golas et al., 1980). On the basis of these considerations, we developed an in situ hybridization procedure for tissue sections that uses RNA oligonucleotide probes for sequence specific detection of miRNAs. RNA oligonucleotide probes with $\sim 20$ nucleotides complementary to an miRNA of interest were chemically synthesized with a $5^{\prime}$-fluorescein as hapten. The choice of RNA oligonucleotides permitted RNase treatment after hybridization to remove nonspecifically bound probe. After hybridization, RNase treatment, and TMAC washes, bound probes were detected with an alkaline phosphatase (AP) -conjugated anti-fluorescein antibody.

The miR-124a miRNA is neural specific (Lagos-Quintana et al., 2002). We detected miR-124a expression throughout the central nervous system (CNS) in sagittal sections of mouse E11.5 and E14.5 embryos after hybridization with an RNA oligonucleotide probe complementary to $20 \mathrm{nt}$ of miR-124a (Fig. 1AC). A probe complementary to the $5^{\prime}$ arm of the stem-loop precursor, miR$124 \mathrm{a}^{*}$, did not generate a signal, nor did a probe for miR-124a with two internal mismatches (miR-124a-m2), indicating that the detection is highly sequence specific (Fig. 1A-C). A probe complementary to the entire 21-nt miR-124a sequence yielded an identical expression pattern at E14.5 (not shown). Un- der the same conditions, a probe with the sequence of the miR-124a reversed (and, thus, not complementary to any known miRNA) generated no signal (Fig. 1C). Expression of miR-124a was low or undetectable in the ventricular zones of the CNS, but present broadly in areas with differentiating neurons. A similar expression pattern was observed in transverse sections of E14.5 spinal cord and in E16.5 brain (not shown). The expression of miR-124a closely resembles the expression of the HuC mRNA (Akamatsu et al., 1999), which encodes an RNA binding protein present in differentiating and mature neurons (Fig. 1C).

We wanted to determine whether the signal we detected after hybridization with the miR-124a probe represented detection of the mature miRNA or detection of either the pre-miRNA stem-loop precursor or the pri-miRNA transcript. The lack of a signal with a probe for the miR-124a* strand suggested that we were not detecting the stem-loop precursor. Identical copies of the miR-124a miRNA are encoded by three different genes, miR-124a1/ a2/a3, located on different chromosomes in the mouse, and all are expressed in the developing CNS (see below). These three genes encode closely related stem-loop precursors, but their sequences diverge completely outside of the stem-loop precursor. We made probes complementary to the miR-124a1 pre-miRNA loop, a sequence in the miR-124a1 primary transcript located 3 ' to the stemloop precursor, or to sequences at the junctions between the miRNA and the precursor/primary transcript (Fig. 1A). None of these probes generated significant signals (Fig. 1C), indicating that the miR-124a probe predominantly detected the mature miRNA.

To confirm that the signal detected with the miR-124a probe was dependent on the expression of the miR124 a miRNA, we transiently transfected undifferentiated mouse P19 embryonal carcinoma cells, which do not express miR-124a, with a vector that expresses the miR-124a1 primary transcript, leading to synthesis of functional mature miR-124a (Yu et al., manuscript in preparation). As controls, P19 cells were transfected with vectors expressing either a multimerized myc epitope tag or a miR- 


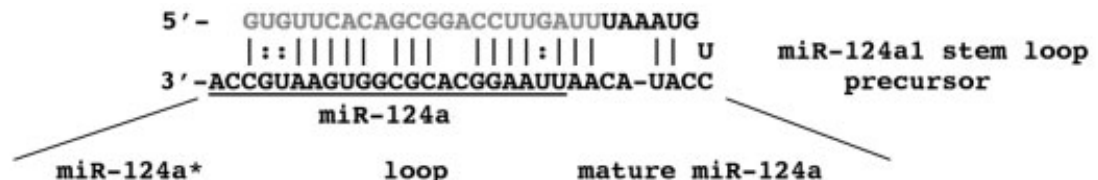

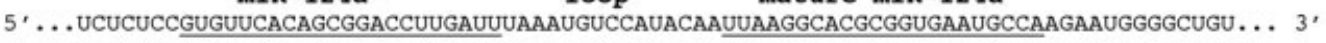
PROBES :

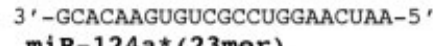

3'-CCACUUACGguUCuUACCCCaa-5'

miR-124a1-J3 (3'junction primary transcript)

3'-AUUCCGaGCGCCAgUUACGGaa-5'

miR124a-m2 (2nt mismatch)

B
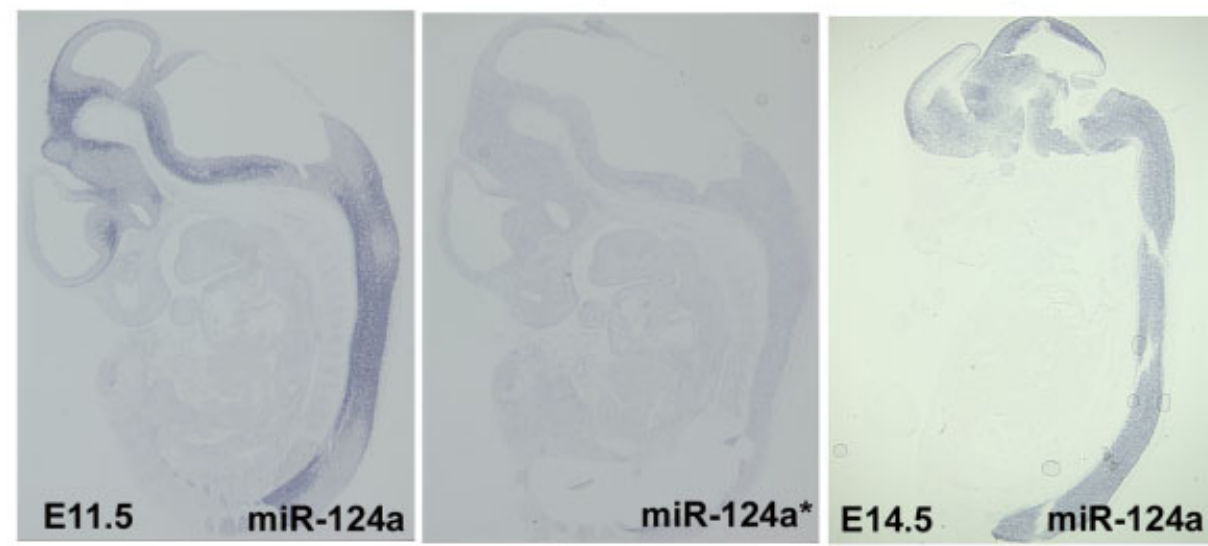

C
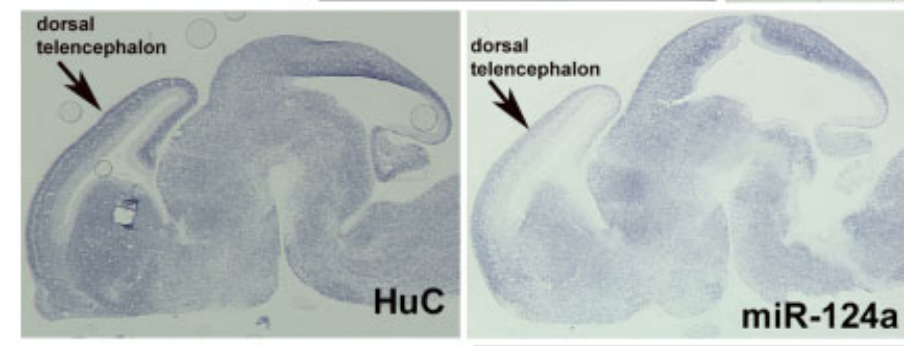

miR-124a-m2
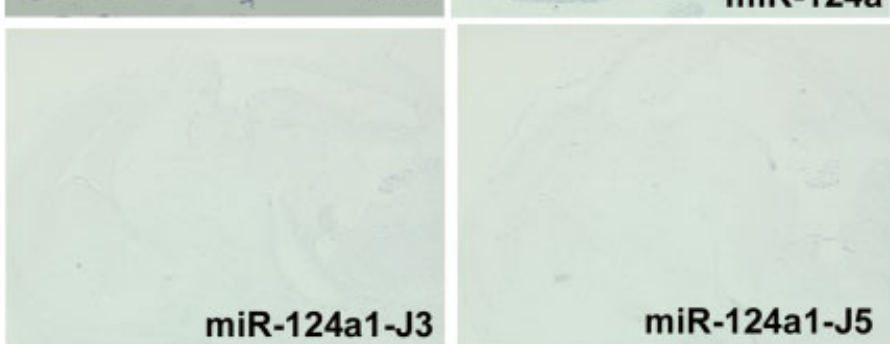

$\operatorname{miR}-124 a^{*}$
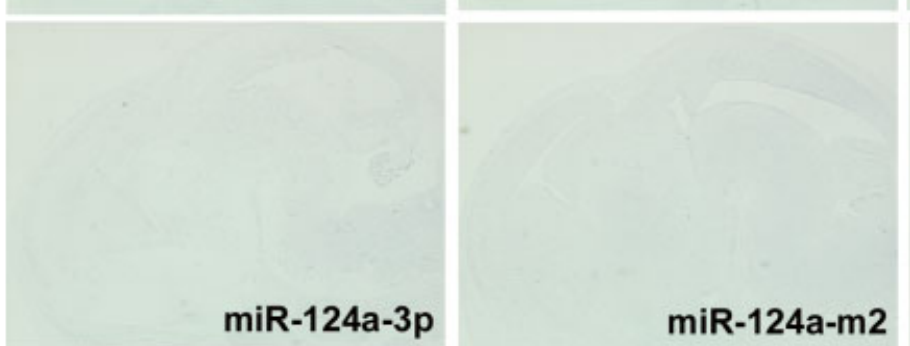

miR-124a1-L

Fig. 1. Detection of miR-124a expression in mouse embryos by in situ hybridization. A: RNA oligonucleotide probes complementary to miR-124a, the miR-124a stem-loop precursor, and/or flanking primary transcript sequences from the miR-124a1 gene. The miR-124a-3p probe is complementary to a sequence in the miR-124a1 primary transcript $3^{\prime}$ to the region shown; the miR-124a-reverse probe is not complementary to a known miRNA. Bases in lower case are not complementary to the target RNA. B: Sagittal sections from embryos at embryonic day (E) 11.5 or E14.5 hybridized with the indicated probes. Two mismatched nucleotides in the miR-124a-m2 probe abolish staining. C: Head regions from E14.5 embryos hybridized with the indicated probes. Expression of miR-124a is similar to HuC, an mRNA expressed in differentiating and mature neurons. Probes against other sequences in the miR-124a1 precursor or primary transcript do not generate a signal, indicating that the miR-124a signal is from the mature miRNA. Processing and staining times were identical for all oligonucleotide probes in $\mathrm{C}$. HuC was detected by standard in situ hybridization using an in vitro transcribed riboprobe. Anterior is to the left in all images. 


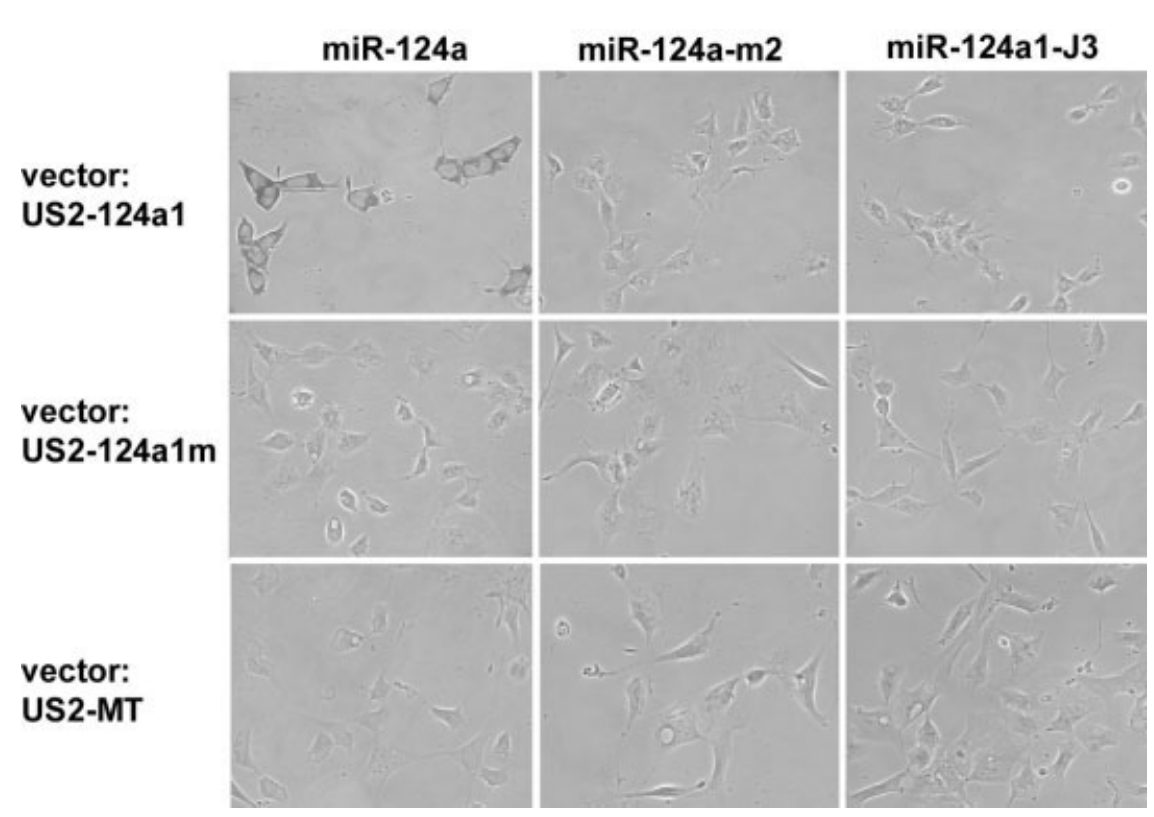

Fig. 2. Detection of miR-124a in $\mathrm{P} 19$ cells transfected with a miR-124a1 expression vector. Cells transfected with a vector expressing miR-124a1, with a mutant version of miR-124a1 with six altered bases in the miRNA, or with a control vector were hybridized with the indicated probes (see Fig. 1A). miR-124a is detected in the cytoplasm of cells transfected with the miR-124a1 vector, but not cells transfected with control vectors. The miR-124a1-J3 probe does not generate a signal, indicating that only the mature miRNA is detected.

$124 \mathrm{a} 1$ primary transcript in which six nucleotides of the mature miR-124a sequence were mutated. In situ hybridization with the miR-124a probe labeled the cytoplasm of cells transfected with the miR-124a1 expression vector, but no signal was detected in cells transfected with the control vectors or hybridized with the miR$124 \mathrm{a}-\mathrm{m} 2$ probe or a probe directed against the junction between the miRNA and the miR-124a1 primary transcript (Fig. 2).

miR-124a originally was isolated from adult mouse brain. In situ hybridization with the miR-124a probe on coronal sections of adult mouse brain labeled cells throughout most of the brain, including the cerebral cortex and hippocampus (Fig. 3). The most intense expression was observed in hippocampal granule cells and the outer layers of the piriform cortex. However, signal was absent from the white matter, suggesting that miR124 a expression may be restricted to neurons. Previous observations using miR-124a sensor construct indicated that miR-124a is expressed in neurons but not glia in culture (Smirnova et al., 2005). The miR-124a signal appeared to localize primarily to the cytoplasm (Fig. 3B), with little or no sig- nal detected in the nucleus, identical to the localization we observed in transfected P19 cells.

We wanted to compare the expression of mature miR-124a with its primary transcripts. Although the miR124a primary transcripts have not been characterized in detail, expressed sequence tags map at or near each miR-124a gene. We obtained a $3.8-\mathrm{kb}$ cDNA that included miR$124 \mathrm{a} 1$, and we used reverse transcriptase-polymerase chain reaction (RTPCR) to isolate cDNAs for the miR$124 \mathrm{a} 2$ and miR-124a3 genes. In vitro transcribed fluorescein-labeled antisense riboprobes were generated for each primary transcript and used for in situ hybridization on mouse E14.5 embryo sections and adult brain sections. All three primary transcript probes labeled cells throughout the CNS, each with a similar pattern, indicating that there is extensive overlap in the expression of the primary transcripts (Fig. 4). The signal from the riboprobe for miR-124a 2 was consistently weaker on embryo sections than the other two primary transcript probes. Similar results were obtained with a miR-124a1 probe that did not contain the miRNA stem-loop region (not shown). No obvious differences were apparent when the mature miR124 a expression detected with oligonucleotide probes (above) was compared with the expression patterns observed for the three miR-124a primary transcripts.

We also examined the expression of miR-9, another neural-specific miRNA that is expressed during neural development and in the adult brain (LagosQuintana et al., 2002; Krichevsky et al., 2003). miR-9 is detected in cells along and near the ventricles of the CNS as well as throughout the dorsal telencephalon at E11.5 (Fig. 5A). The expression of miR-9 is roughly complimentary to that of miR-124a at E11.5. At E14.5, miR-9 expression is maintained throughout the developing cerebral cortex, but strong expression of miR-9 appears reduced to a single layer of cells lining the ventricles in the remainder of the CNS (Fig. 5B). For most miRNAs, one strand of the stem-loop precursor is present as a mature miRNA, whereas a mature miRNA derived from the complementary “*” strand is much less abundant or undetectable (Lagos-Quintana et al., 2001; Lau et al., 2001; Lee and Ambros, 2001). However, miR-9* (originally named miR-131) is readily detected in the developing and adult brain by cloning and Northern blot analyses (Lagos-Quintana et al., 2002; Krichevsky et al., 2003). Consistent with this finding, in situ hybridization using a probe complementary to miR-9* detects a pattern of expression similar to miR-9 at E14.5. Like miR$124 \mathrm{a}$, identical copies of miR-9/miR-9* are encoded by three separate genes in the mouse (miR-9-1/2/3). A riboprobe complementary to the miR-9-2 primary transcript produced a pattern indistinguishable from miR-9/9* when used for in situ hybridization (Fig. $5 \mathrm{~B})$. In the adult brain, expression of miR-9 and the miR-9-2 primary transcript were still detectable in the subventricular zone near the lateral ventricles, a site of adult neurogenesis in the mouse (Fig. 5C), as well as in the hippocampus (not shown). In contrast to miR-9 and miR-124a, the unrelated miR-92 microRNA was detected throughout the nervous system and also in non-neural tissue (Fig. 5A,B). The miR-92 signal was slightly more intense near the ventricles, and intriguingly, in the developing vestibu- 
locochlear ganglion. A similar pattern was observed with a probe for miR$19 \mathrm{~b}$ (data not shown), a miRNA that is contained in the same genomic cluster as miR-92 (Lee et al., 2002; Tanzer and Stadler, 2004).

In situ hybridization with a probe for miR-204 revealed that, within the brain, miR-204 is expressed specifically in the choroid plexus but not in neural structures, both in E14.5 embryos and in the adult (Fig. 6A,C). As miR-204 expression previously had not been reported in the choroid plexus, we confirmed its expression using Northern blot analysis of RNA from dissected adult tissues (Fig. 6B). miR-204 was detected in RNA from the choroid plexus, but not the cerebral cortex, whereas the neural-specific miR-124a was detected in the cortex and not the choroid plexus. miR204 is located within the sixth intron of the transient receptor potential melastatin 3 (TRPM3) cation channel and is transcribed in the same direction as TRPM3 (Grimm et al., 2003; Lagos-Quintana et al., 2003; Rodriguez et al., 2004). TRPM3 is expressed in choroid plexus and eye (Oberwinkler et al., 2005). In situ hybridization with a riboprobe complementary to the TRPM3 mRNA (spanning exons 10-18) specifically labeled the choroid plexus but not surrounding neural tissues, confirming that TRPM3 and miR-204 are coexpressed. In situ hybridization with a riboprobe complementary to the TRPM3 intron 6 mostly labeled nuclei, while the miR204 signal was primarily cytoplasmic (Fig. 6D,E), indicating that the miR204 probe is not detecting intronic RNA from the TRPM3 gene.

The miR-204 miRNA was originally isolated from the mouse eye. In situ hybridization with the miR-204 probe on adult mouse eye sections strongly labeled the retinal pigment epithelium (RPE) and the ciliary body (Fig. $7 \mathrm{~A}, \mathrm{C})$. A weaker signal was also detected in a subset of cells in the inner nuclear layer of the retina. miR-224 was expressed in a similar pattern in the eye (Fig. 7A), and like miR-204, miR-224 is expressed in the choroid plexus but not other brain tissue (data not shown). In contrast, miR-124a was detected in most cells in the neural retina but not in the RPE (Fig. 7B).
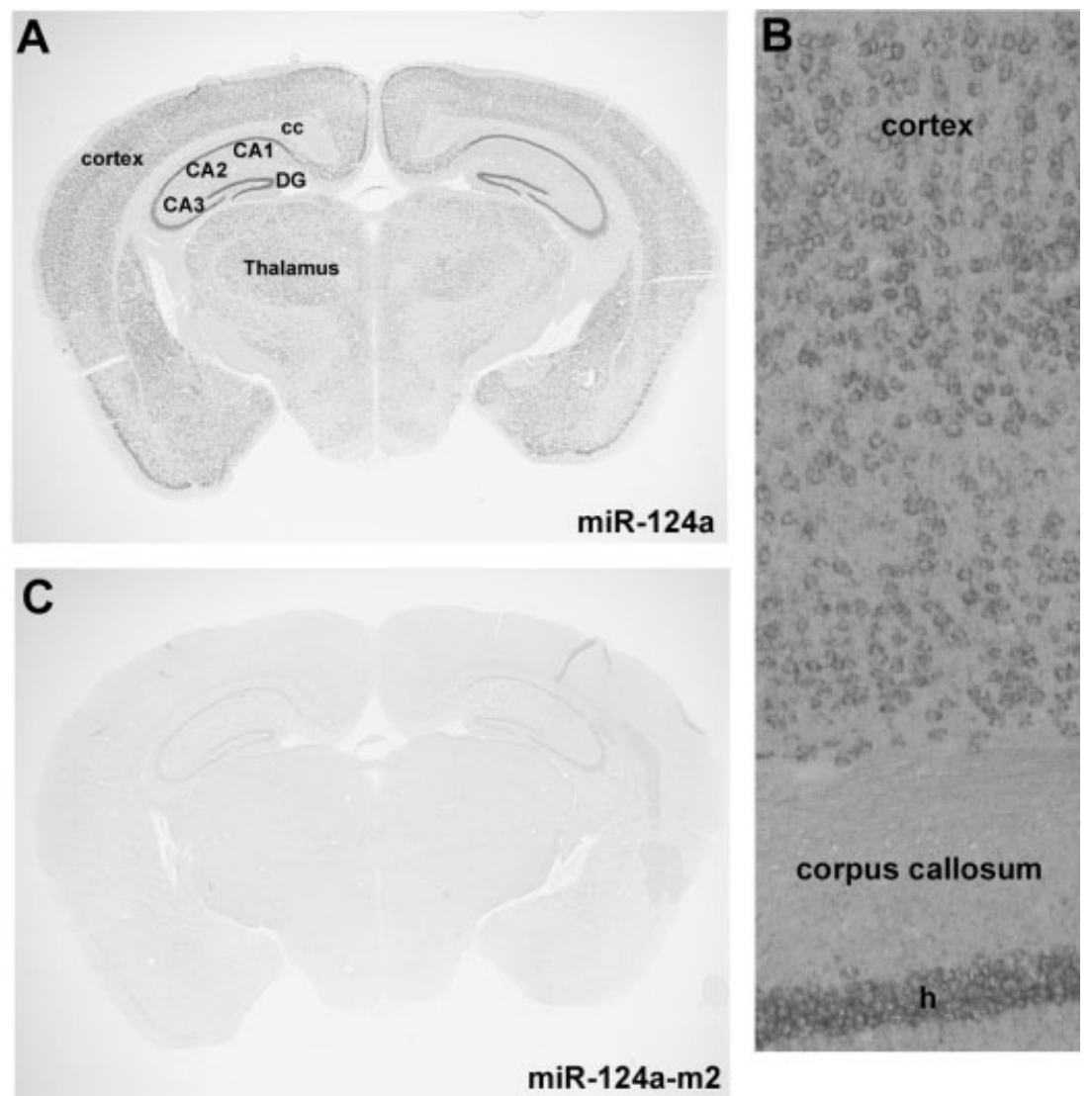

Fig. 3. Expression of miR-124a in adult mouse brain. A: miR124a is detected in neurons of the cerebral cortex and hippocampus/dentate gyrus (CA1-3/DG), whereas the miR-124a-m2 mismatch probe generates little signal. Expression is not detected in the corpus callosum (cc), suggesting that miR-124a expression is not expressed in glial cells. B: Higher magnification view of cortex and hippocampal granule cell layer $(\mathrm{H})$. The signal from miR124a appears localized mostly to the cytoplasm.

\section{DISCUSSION}

We describe here a novel in situ hybridization method for determining spatial expression patterns of miRNAs in tissue sections. We have used synthetic fluorescein-labeled RNA oligonucleotides as hybridization probes, permitting the use of RNase digestion to remove unbound probe. Fluorescein-labeled DNA oligonucleotide probes also detected endogenous miRNAs, but with substantially higher background on tissue sections, possibly from nonspecifically bound probe (unpublished observations). To provide sequence specificity, we have used TMAC-based washes similar to those used for allele-specific oligonucleotide probes (Litt et al., 1998). For the abundant miRNA miR-124a, we found that two single nucleotide mismatches with the probe essentially abolished the hybridization signal. Using this method, we have determined expres- sion patterns for several neural-specific miRNAs.

While this work was in progress, a different in situ method for the detection of mammalian miRNAs was reported, based on the use of LNA probes (Kloosterman et al., 2006; Nelson et al., 2006). We have focused on detection of miRNA expression in tissue sections and cell culture, whereas in situ hybridization with LNA probes has been applied to whole mount zebrafish and mouse (Wienholds et al., 2005; Kloosterman et al., 2006), as well as to human brain sections (Nelson et al., 2006) and Drosophila embryos (Sokol and Ambros, 2005). In contrast to our results, it was reported that RNA or DNA oligo probes failed to detect miRNAs (Kloosterman et al., 2006). This discrepancy may reflect the different conditions used, and/or different labeling efficiencies for the probes. As we have observed with 
A
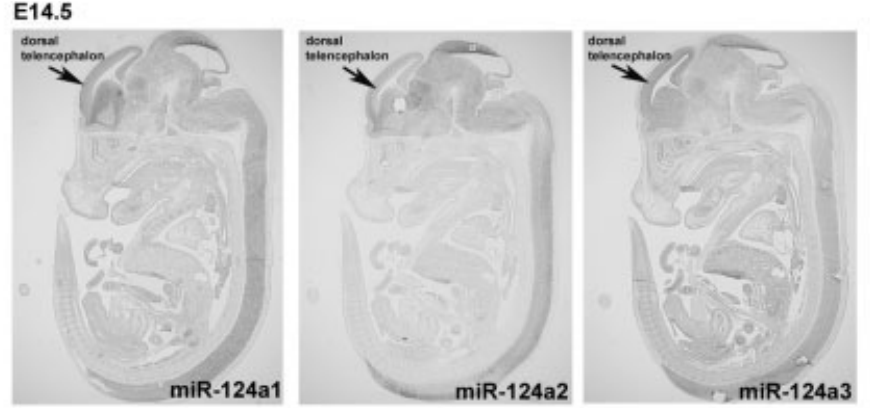

\section{B}
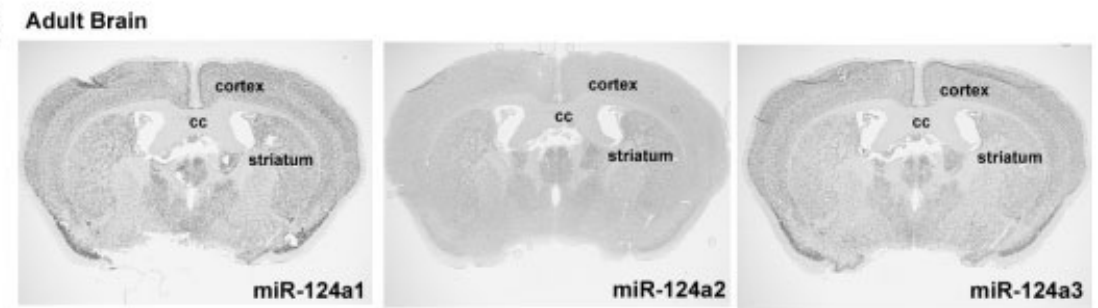

Fig. 4. Expression of miR124a1-3 primary transcripts. A: Sagittal sections of embryonic day (E) 14.5 mouse embryos showing the expression patterns for miR-124a1, miR-124a2, and miR-124a3 detected with riboprobes. B: Detection of 124a1, 124a2, and 124a3 primary transcripts in adult mouse brains by in situ hybridization with antisense riboprobes. The primary transcripts are not detected in the corpus callosum (cc).

RNA probes, LNA probes were able to distinguish closely related miRNA sequences, and the expression patterns observed with either method appear similar (see below). One difference between the two methods is that we have used TMAC washes to make the $\mathrm{Tm}$ for probe duplexes independent of base composition, allowing probes for different miRNAs to be processed under identical conditions. In contrast, optimal specificity using the LNA probes as described for mammalian tissue requires that hybridization conditions are adjusted for each probe with a different Tm (Kloosterman et al., 2006). The ability to use a single set of conditions for all probes should facilitate comparative in situ analyses with multiple miRNA probes.

One concern with in situ detection of miRNA sequences is whether observed signals derive from a mature miRNA or from a miRNA precursor or primary transcript. Probes complementary to sequences in the stem-loop precursor, the primary transcript, or the junctions between these sequences and the miR-124a miRNA failed to detect the miR-124a1 gene, whereas a probe complementary to mature miR-124a generated a robust signal. These observations are consistent with the observation that miR-
NAs are processed efficiently from precursors and accumulate to high levels in cells and indicate that we are mainly detecting mature miRNAs. We also examined the expression of primary transcripts for the three miR124a genes and the miR-9-2 gene. The expression patterns of primary transcripts and mature miRNAs appeared similar, suggesting that production of these miRNAs is regulated largely at the level of transcription.

We find that miR-124a is expressed in differentiating and mature neurons throughout most of the CNS. In contrast, miR-9 appears to be expressed in neural precursors in much of the CNS, although it is also expressed in differentiated cells in the telencephalon. Hybridization with probes for other miRNAs gave distinct patterns in both embryos and the adult brain (data not shown). The expression patterns we observed for miR-124a, miR-9, and miR-92 miRNAs in sections of E11.5 and E14.5 mouse embryos appear consistent with the patterns observed with LNA probes in whole-mount E10.5 mouse embryos and in zebrafish (Wienholds et al., 2005; Kloosterman et al., 2006). Expression patterns for miR-124a and miR-9 in adult mouse brain appear similar to expression in adult human brain detected with LNA probes (Nelson et al., 2006), except that we observe expression of miR-9 in the mouse subventricular zone. This finding may reflect differences in adult neurogenesis between rodents and humans (Bedard and Parent, 2004).

The functional roles of most mammalian neural miRNAs, including miR-124a and miR-9, are not yet understood. It has been proposed that miR-124a plays a role in neuronal identity by triggering degradation of non-neuronal mRNAs (Lim et al., 2005; Conaco et al., 2006). Krichevsky et al. (2005) recently reported that overexpression of miR-124a and miR9/9* together in embryonic stem cells undergoing neural differentiation increased the number of neurons relative to glia, while blocking miR-9 function in this system reduced the number of neurons relative to glia. Their observations suggest that miR-9 and miR-124a may play a role in neural cell fate decisions. Our in situ hybridization results indicate that the extent of miR-9 expression in the ventricular zones becomes more restricted as CNS development progresses, except in the telencephalon (Fig. 5). An intriguing possibility is that the restriction of miR-9 expression could contribute to the developmental shift from neuron generation to glial cell generation. We have found that, in mouse P19 cells differentiating as neurons, overexpression of miR-124a enhances neurite outgrowth whereas blocking miR-124a function delays neurite outgrowth, and overexpression of miR-124a or blocking miR-124a function in primary cortical neurons differentiating in vitro also alters neurite outgrowth (J-Y. Yu et al., manuscript in preparation). These observations suggest a role for miR-124a in regulating neuronal differentiation, consistent with its widespread expression in differentiating neurons.

miR-204 was originally isolated from the eye, and we observed that miR-204 is highly expressed in the RPE and the ciliary body. miR-204 also is specifically expressed in the choroid plexus. Both the choroid plexus and the ciliary body are involved in the secretion of fluids (the cerebrospinal fluid and the aqueous humor, respectively), suggesting that miR-204 could have a regulatory role in this process. The miR-204 miRNA 
is located in the intron of the TRPM3 gene, and TRPM3 is also expressed in the choroid plexus, suggesting that the miRNA and TRPM3 are derived from a single transcription unit in that tissue. TRPM3 encodes a cation channel, but its biological function is not known (Grimm et al., 2003; Oberwinkler et al., 2005). A subset of miRNAs is located within the introns of protein coding genes (Rodriguez et al., 2004), and analysis of microarray data has shown that the expression of several intronic miRNAs is correlated with the expression of the mRNA from the same locus (Baskerville and Bartel, 2005). However, in Drosophila, at least some intronic miRNAs may not be coregulated with the corresponding mRNA (Aboobaker et al., 2005).

Using in situ hybridization, we have demonstrated that several neural miRNAs are expressed in specific but distinct patterns during embryonic development in the mouse. We also have identified a new expression domain for miR-204, the choroid plexus, which was not previously known to be a site of miR-204 expression. It is likely that in situ hybridization will allow the detection of miRNAs that are expressed in only small numbers of cells. In addition, the ability to detect the spatial patterns of miRNA expression should facilitate the analysis of miRNA function.

\section{EXPERIMENTAL PROCEDURES}

\section{In Situ Hybridization}

Embryos were fixed by overnight immersion in $4 \%$ paraformaldehyde (4\% PFA) in phosphate buffered saline (PBS) at $4^{\circ} \mathrm{C}$, washed in PBS, dehydrated in $15 \%$ sucrose, and embedded in OCT (Fisher). Twelve-micrometer sections were cut on a cryostat, transferred to Superfrost/plus microscope slides (Fisher), and stored at $-20^{\circ} \mathrm{C}$.

Detection of mRNAs by in situ hybridization with riboprobes was essentially as described by Birren and Anderson (Birren et al., 1993), except that riboprobes were synthesized by in vitro transcription with UTP-fluorescein (Roche) and detection used an anti-fluorescein Fab2 fragment conjugated to AP (Roche 1426338), pre-absorbed with mouse embryo powder.
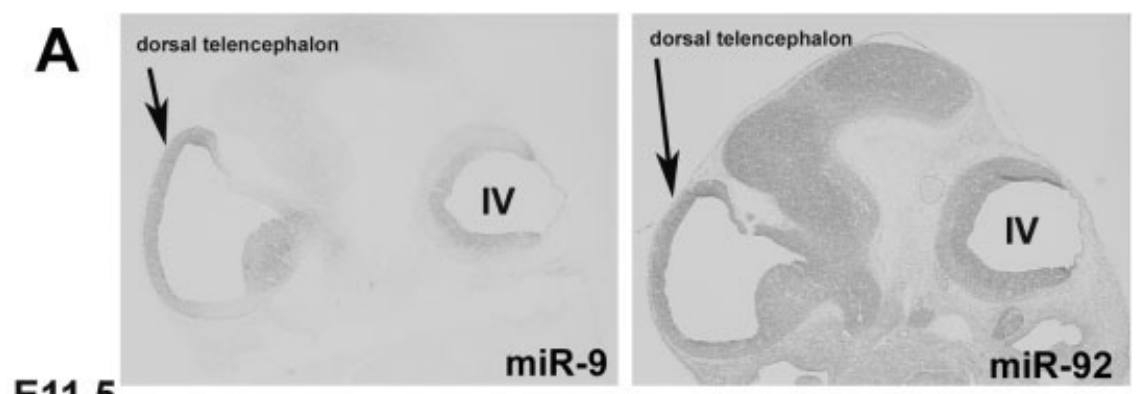

E11.5
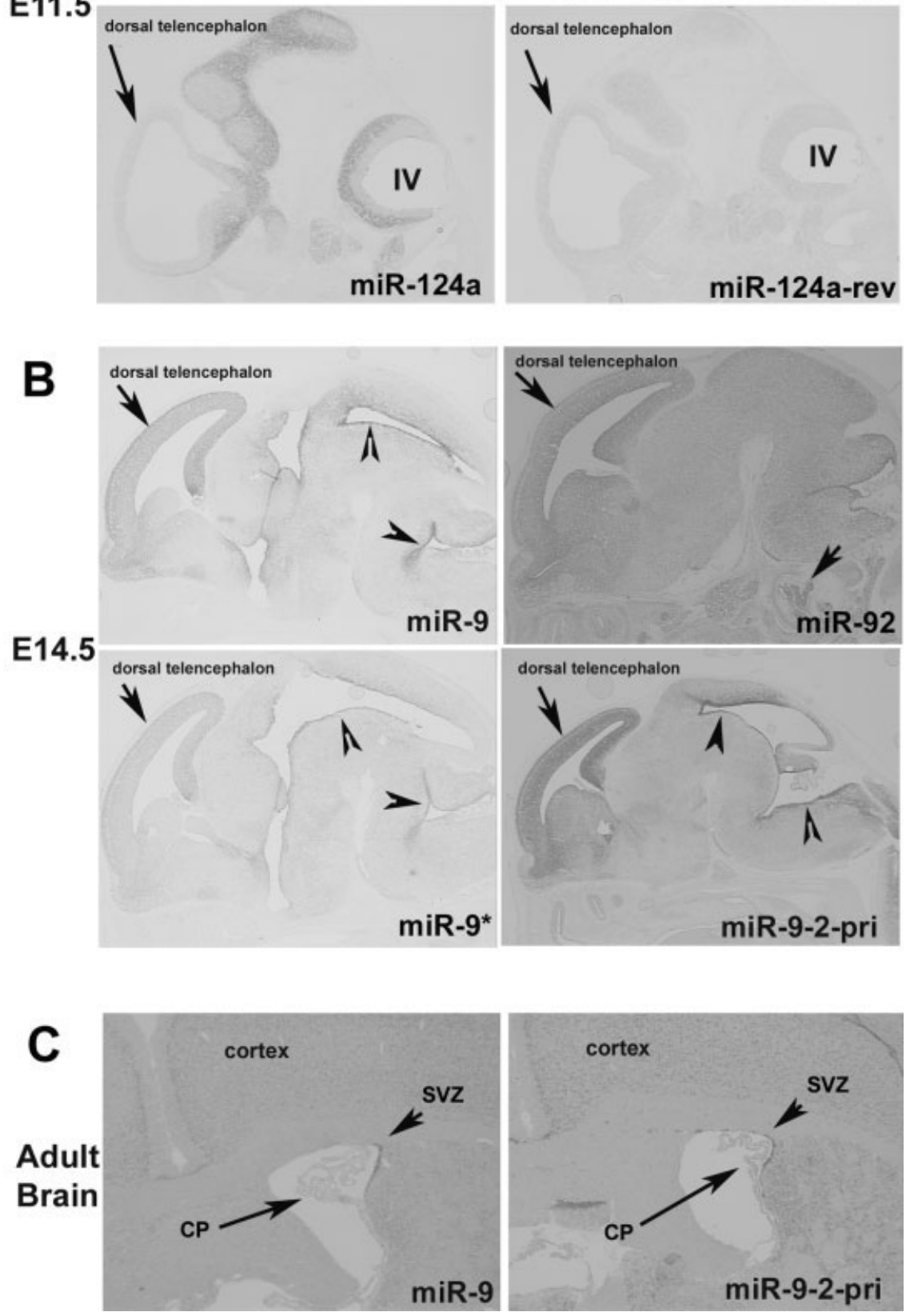

Fig. 5. Expression of miR-9 and miR-92 miRNAs in the developing central nervous system (CNS). A: In embryonic day (E) 11.5 embryos, miR-9 is expressed in the neuroepithelium near the ventricles, in a pattern mostly complementary to miR-124a. In contrast, an unrelated miRNA miR-92 is expressed throughout most of the brain, although the most intense signals are near the ventricles (fourth ventricle: IV) B: At E14.5, miR-9 is restricted to cells lining the ventricles (arrowheads), except in the dorsal telencephalon where it is widely expressed. $m i R-9^{*}$ is present in a similar pattern, as is a primary transcript for miR-9/9* (miR-9-2-pri: detected by conventional in situ hybridization with a riboprobe). The miR-92 miRNA is widely expressed, although the signal is more intense in the developing vestibulocochlear ganglion (arrow). C: In the adult brain, miR-9 and the miR-9-2 primary transcript are detected in the subventricular zone (SVZ). CP, choroid plexus. 


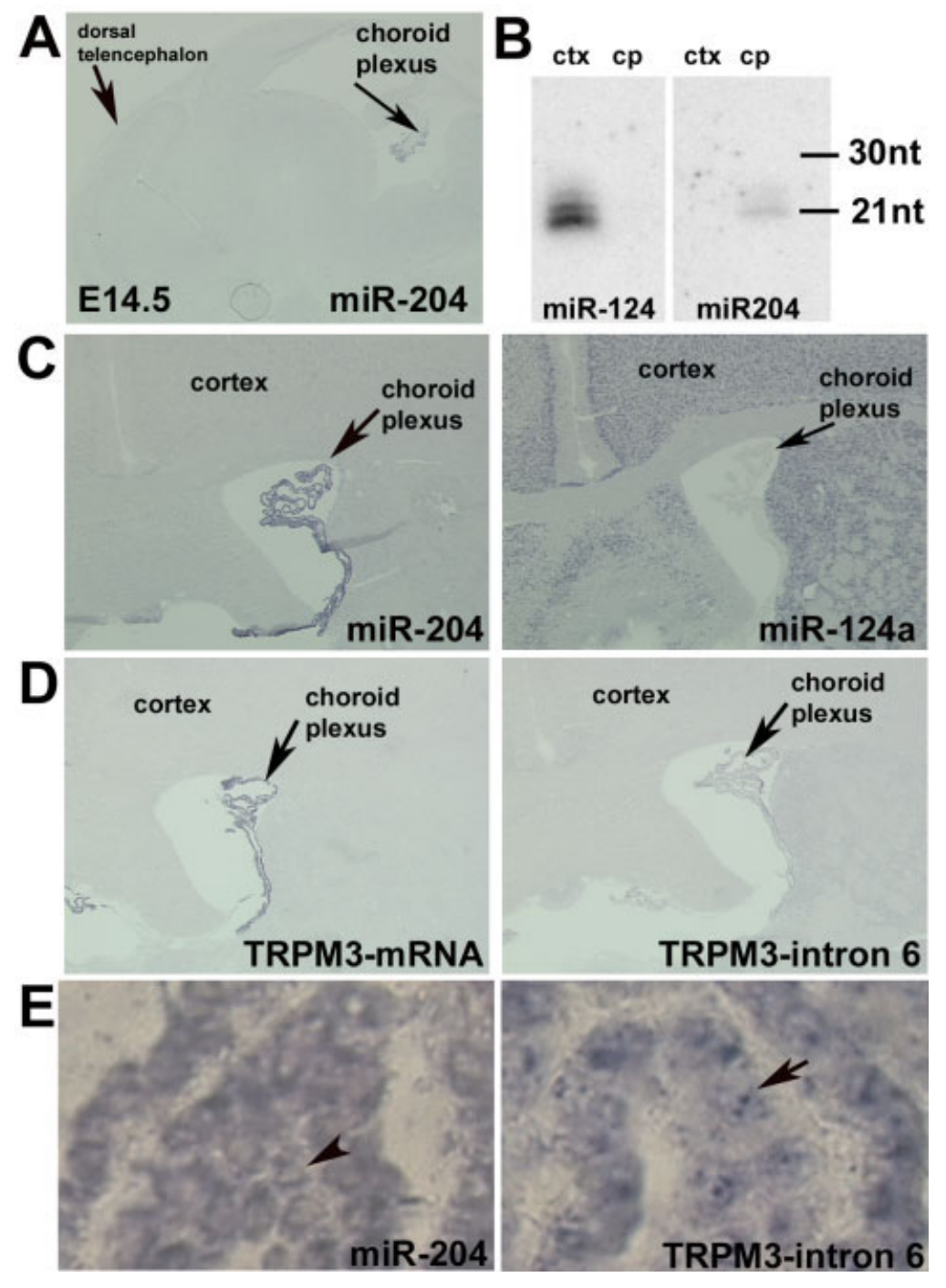

Fig. 6. miR-204 and transient receptor potential melastatin 3 (TRPM3) are coexpressed in choroid plexus. A: At embryonic day $(E) 14.5$ miR-204 is detected in the choroid plexus of the 4 th ventricle. B: Northern blot of RNA from adult cerebral cortex (ctx) and choroid plexus (cp) probed for miR-204 and later reprobed for miR-124a. miR-204 is detected only in choroid plexus, whereas miR-124a is detected only in cortex. C: In situ hybridization with miR-204 and miR-124a probes on adult mouse brain sections detects miR-204 but not miR-124a in the choroid plexus. D: miR-204 is located in intron 6 of the TRPM3 gene. A riboprobe for the TRPM3 mRNA labels the choroid plexus, whereas a probe against part of TRPM3 intron 6 ( $3^{\prime}$ to the miR-204 sequence) weakly labels the choroid plexus. E: Higher magnification images of miR-204 and the TRPM3 intron 6 probe show that miR-204 labels primarily a ring of cytoplasm in each cell, whereas the most intense signal with the TRPM3 intron 6 probe is punctate.

Riboprobes for primary transcripts were made by $\mathrm{T} 7$ in vitro transcription: a cDNA for miR-124a1 (IMAGE clone BC030402, Invitrogen, 3,837 bp) was subcloned into CS2p+ (Rupp et al., 1994; Turner and Weintraub, 1994). The miR-124a2 probe $(2,264$ bp) was isolated by RT-PCR from embryonic day (E) 14.5 mouse brain RNA using primers gagaattcGCAAGGGATGCTGTGAAAAGAG and gactcgagAGAAAGCCTTGCTGAGAGCCAC (added restriction sites in lower case).
gaggatccCCATCATTGAGCCCATAACTTTCC and gactcgagGCTGTGACCCTTTAATTCAGTTCC, and TPRM3-mRNA (exon): gaggatccACAGAGTTGACATCGCTCGCAG and gactcgagTGATTCCCCATTGCTTCGCC. All PCR products were subcloned into the CS2p+ vector.

Detection of microRNAs by in situ hybridization with oligoribonucleotide probes used a modification of the procedure for riboprobes. Buffers and specific conditions were chosen to optimize signal detection and sequence specificity based on preliminary experiments with probes for miR-124a and other miRNAs (data not shown). Steps were at room temperature unless specified otherwise. Slides were warmed at $37^{\circ} \mathrm{C}$ for $30 \mathrm{~min}$, fixed in 4\% PFA in PBS for $20 \mathrm{~min}$, and rinsed twice in PBS for 10 min each. Tissue was then treated with $10 \mu \mathrm{g} / \mathrm{ml}$ Proteinase $\mathrm{K}$ (Roche) in $50 \mathrm{mM}$ Tris $\mathrm{pH}$ 7.5 with $5 \mathrm{mM}$ ethylenediaminetetraacetic acid (EDTA) for $6 \mathrm{~min}$, washed in PBS for $10 \mathrm{~min}$, then fixed in $4 \% \mathrm{PFA}$ in PBS for $15 \mathrm{~min}$. Slides were incubated with $2.5 \mathrm{mM}$ acetic anhydride in $0.1 \mathrm{M}$ tetraethanolamine twice, for $5 \mathrm{~min}$ each. Slides were washed in PBS for 20 min and prehybridized in hybridization buffer at $37^{\circ} \mathrm{C}$ for $2.5 \mathrm{hr}$. Hybridization buffer: $50 \%$ formamide, $0.3 \mathrm{mg} / \mathrm{ml}$ yeast RNA (ICN), $100 \mathrm{mg} / \mathrm{ml}$ heparin, $1 \times$ Denhardt's solution $(0.2 \%$ BSA, $0.2 \%$ polyvinylpyrrolidone, $0.2 \%$ Ficoll 400), $0.1 \%$ Tween 20, 0.1\% CHAPS, $5 \mathrm{mM}$ EDTA, and $0.3 \mathrm{nmol} / \mathrm{ml} 12$-mer random sequence DNA oligonucleotides. Fresh hybridization buffer with 1 $\mu \mathrm{g} / \mathrm{ml}$ oligoribonucleotide probe was added, and hybridization was performed at $37^{\circ} \mathrm{C}$ for $17-18 \mathrm{hr}$. Slides were washed once in $2 \times$ standard saline citrate (SSC) for $15 \mathrm{~min}$ at $37^{\circ} \mathrm{C}$, treated with $10 \mu \mathrm{g} / \mathrm{ml}$ RNase A (Roche) in $2 \times \mathrm{SSC}$ for $30 \mathrm{~min}$ at $37^{\circ} \mathrm{C}$, and washed twice with $2 \times$ SSC for 15 min each. Three stringent washes were performed using 3 M TMAC and $0.2 \%$ Tween 20 in $50 \mathrm{mM}$ Tris $\mathrm{pH} 8.0$ at $54^{\circ} \mathrm{C}$. The first two washes were for $5 \mathrm{~min}$ and the third for $10 \mathrm{~min}$. Slides were then rinsed twice with $0.1 \%$ Triton X-100 in PBS for $10 \mathrm{~min}$, and blocked for $1 \mathrm{hr}$ in $20 \%$ sheep serum (Jackson Laboratories) and 0.1\% Triton X-100 in PBS. Slides were incubated with preabsorbed anti-fluores- 
cein-AP in $\mathrm{PBS}$ with $0.1 \%$ Triton $\mathrm{X}-100$ for $4 \mathrm{hr}$, rinsed once in PBS with $0.1 \%$ Triton X-100 for $10 \mathrm{~min}$, then rinsed overnight in PBS with $0.1 \%$ Triton X-100 at $4^{\circ} \mathrm{C}$. Sections were rinsed twice for 5 min with AP buffer $(100 \mathrm{mM}$ Tris $\mathrm{pH} 9.5,50 \mathrm{mM}$ $\mathrm{MgCl}_{2}, 100 \mathrm{mM} \mathrm{NaCl}, 0.1 \%$ Tween 20 ) and then incubated with BCIP (350 $\mu \mathrm{g} / \mathrm{ml})$ and NBT $(75 \mu \mathrm{g} / \mathrm{ml})$ in AP buffer to detect AP (reaction done in the dark). Staining time varied depending on tissue age and probe, but typically was 2-6 hr. After the reaction was complete, slides were rinsed with PBS and fixed in 4\% PFA in PBS for $10 \mathrm{~min}$, and rinsed again with PBS. Slides were mounted with aquapoly/mount (Polysciences Inc., \#18606).

Oligoribonucleotides were synthesized with a $5^{\prime}$ fluorescein modification (50 nmol scale, Invitrogen) and purified on $18 \%$ polyacrylamide gels. Gel purification reduced background from unincorporated fluorescein. Probe sequences: miR-9, UCAUACAGCUAGAUAACCAAAGA; miR-92, 5' -AGGCCGGGACAAGUGCAAUA; miR-204, 5'-GCAUAGGAUGACAAAGGGAA; miR-224, 5'-AACGGAACCACUAGUGACUU; see Figure 1 for miR-124a probe sequences.

\section{Northern Blots}

A total of $15 \mu \mathrm{g}$ of total RNA was separated by electrophoresis on 18\% polyacrylamide denaturing gels, transferred with a GENIE electroblotter (Idea Scientific) onto Hybond-N+ membrane (Amersham Pharmacia Biotech), and ultraviolet crosslinked. DNA oligonucleotide probes and RNA oligonucleotide size markers were $5^{\prime}$ end labeled with $\alpha_{-}{ }^{32} \mathrm{P}-\mathrm{ATP}$ using T4 polynucleotide kinase. Hybridization was performed at $42^{\circ} \mathrm{C}$ in Church-Gilbert solution ( $1 \mathrm{mM}$ EDTA, $0.25 \mathrm{M}$ $\mathrm{Na}_{2} \mathrm{HPO}_{4}, 7 \%$ sodium dodecyl sulfate [SDS]) overnight. Membranes were washed at $42^{\circ} \mathrm{C}$, twice with $2 \times \mathrm{SSPE} /$ $0.1 \%$ SDS and once with $0.5 \times \mathrm{SSPE} /$ $0.1 \%$ SDS. Blots were exposed in the Storage Phosphor Screen (Molecular Dynamics) at room temperature for 48-72 hr. Images were obtained with IPLab Gel H $1.5 \mathrm{~g}$ software (Signal Analytics) from PhosphorImager 445 SI (Molecular Dynamics). Blots were stripped by boiling in $0.1 \%$ SDS $/ 0.1 \times$ SSC solution for $20 \mathrm{~min}$ for reprobing.
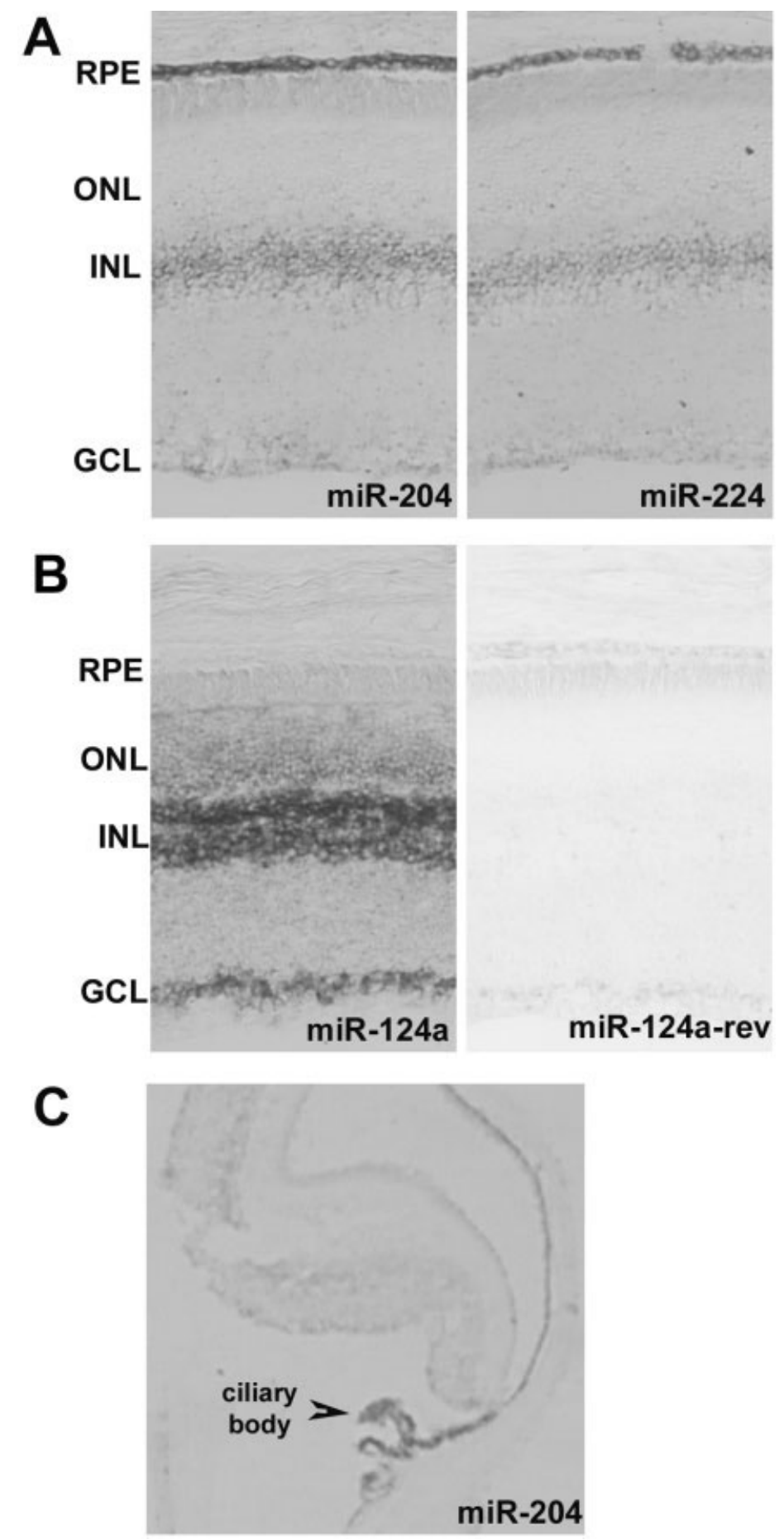

Fig. 7. miRNA expression in adult mouse eye. A: miR-204 and miR-224 are expressed in retina pigment epithelium (RPE) and a subset of cells in the inner nuclear layer (INL) of the neural retina. ONL, outer nuclear layer (photoreceptors); GCL, ganglion cell layer. B: miR-124a is expressed in most cells in the neural retina but not in RPE. A retina hybridized with the miR-124a-reverse (rev) control probe is also shown. C: miR-204 is also expressed in the ciliary body.

\section{Cell Culture and Vectors}

P19 cells were cultured and transfected as described previously (Farah et al., 2000; Yu et al., 2003). A total of $1.2 \mu \mathrm{g}$ of US2-MT (control; mRNA for myc epitope tags, driven by human ubiquitin C promoter), US2-124a1 (contains part of the miR-124a1 primary transcript), or US2-124a1m (a mutant variant with nucleotides 1-6 
of miR-124a altered; Yu et al., manuscript in preparation) was cotransfected with $0.5 \mu \mathrm{g}$ of US2-puro into P19 cells in 12 well plates. Cells were split 1:10 eleven hr after transfection onto Superfrost/plus Microscopic slides coated with poly-L-lysine and mouse natural laminin (Invitrogen), and $15 \mu \mathrm{g} / \mathrm{ml}$ puromycin was added. $48 \mathrm{hr}$. after transfection, cells were fixed in $4 \%$ PFA in PBS for $20 \mathrm{~min}$, rinsed twice with $\mathrm{PBS}$, and stored in PBS at $4^{\circ} \mathrm{C}$ until in situ hybridization was performed as described above.

\section{ACKNOWLEDGMENTS}

We thank Paresh Patel, Anne Vojtek, and Dave Engelke for helpful discussions. We also thank Xiang Jianming and Richard Keep for advice on isolation of choroid plexus tissue and Jennifer Taylor and Kate Meyer for assistance with cryostat sectioning. D.L.T. was funded by a grant from the Wilson Medical Research Foundation.

\section{REFERENCES}

Aboobaker AA, Tomancak P, Patel N, Rubin GM, Lai EC. 2005. Drosophila microRNAs exhibit diverse spatial expression patterns during embryonic development. Proc Natl Acad Sci U S A 102:18017-18022.

Akamatsu W, Okano HJ, Osumi N, Inoue T, Nakamura S, Sakakibara S, Miura M, Matsuo N, Darnell RB, Okano H. 1999. Mammalian ELAV-like neuronal RNAbinding proteins $\mathrm{HuB}$ and $\mathrm{HuC}$ promote neuronal development in both the central and the peripheral nervous systems. Proc Natl Acad Sci U S A 96:9885-9890.

Bagga S, Bracht J, Hunter S, Massirer K, Holtz J, Eachus R, Pasquinelli AE. 2005. Regulation by let-7 and lin-4 miRNAs Results in Target mRNA Degradation. Cell 122:553-563.

Baskerville S, Bartel DP. 2005. Microarray profiling of microRNAs reveals frequent coexpression with neighboring miRNAs and host genes. RNA 11:241-247.

Bedard A, Parent A. 2004. Evidence of newly generated neurons in the human olfactory bulb. Brain Res Dev Brain Res 151:159-168.

Bentwich I, Avniel A, Karov Y, Aharonov R, Gilad S, Barad O, Barzilai A, Einat P, Einav U, Meiri E, Sharon E, Spector Y, Bentwich Z. 2005. Identification of hundreds of conserved and nonconserved human microRNAs. Nat Genet 37:766-770.

Berezikov E, Guryev V, van de Belt J, Wienholds E, Plasterk RH, Cuppen E. 2005. Phylogenetic shadowing and computational identification of human microRNA genes. Cell 120:21-24.
Birren SJ, Lo L, Anderson DJ. 1993. Sympathetic neuroblasts undergo a developmental switch in trophic dependence. Development 119:597-610.

Brennecke J, Hipfner DR, Stark A, Russell RB, Cohen SM. 2003. bantam encodes a developmentally regulated microRNA that controls cell proliferation and regulates the proapoptotic gene hid in Drosophila. Cell 113:25-36.

Conaco C, Otto S, Han JJ, Mandel G. 2006. Reciprocal actions of REST and a microRNA promote neuronal identity. Proc Natl Acad Sci U S A 103:2422-2427.

Dostie J, Mourelatos Z, Yang M, Sharma A, Dreyfuss G. 2003. Numerous microRNPs in neuronal cells containing novel microRNAs. RNA 9:180-186.

Farah MH, Olson JM, Sucic HB, Hume RI, Tapscott SJ, Turner DL. 2000. Generation of neurons by transient expression of neural bHLH proteins in mammalian cells. Development 127:693-702.

Golas T, Miller M, Shugar D. 1980. The effects of tetraalkylammonium salts on helix-coil transition parameters in natural and synthetic ribo- and deoxyribopolynucleotides. Chem Biol Interact 30: 209-222.

Gregory RI, Yan KP, Amuthan G, Chendrimada T, Doratotaj B, Cooch N, Shiekhattar R. 2004. The Microprocessor complex mediates the genesis of microRNAs. Nature 432:235-240.

Grimm C, Kraft R, Sauerbruch S, Schultz G, Harteneck C. 2003. Molecular and functional characterization of the melastatinrelated cation channel TRPM3. J Biol Chem 278:21493-21501.

Hutvagner G, McLachlan J, Pasquinelli AE, Balint E, Tuschl T, Zamore PD. 2001. A cellular function for the RNAinterference enzyme Dicer in the maturation of the let-7 small temporal RNA. Science 293:834-838.

Jacobs KA, Rudersdorf R, Neill SD, Dougherty JP, Brown EL, Fritsch EF. 1988. The thermal stability of oligonucleotide duplexes is sequence independent in tetraalkylammonium salt solutions: application to identifying recombinant DNA clones. Nucleic Acids Res 16:4637-4650.

Johnston RJ, Jr., Chang S, Etchberger JF, Ortiz CO, Hobert O. 2005. MicroRNAs acting in a double-negative feedback loop to control a neuronal cell fate decision. Proc Natl Acad Sci U S A 102:1244912454.

Ketting RF, Fischer SE, Bernstein E, Sijen T, Hannon GJ, Plasterk RH. 2001. Dicer functions in RNA interference and in synthesis of small RNA involved in developmental timing in C. elegans. Genes Dev 15:2654-2659.

Kloosterman WP, Wienholds E, de Bruijn E, Kauppinen S, Plasterk RH. 2006. In situ detection of miRNAs in animal embryos using LNA-modified oligonucleotide probes. Nat Methods 3:27-29.

Krichevsky AM, King KS, Donahue CP, Khrapko K, Kosik KS. 2003. A microRNA array reveals extensive regulation of microRNAs during brain development. RNA 9:1274-1281.
Krichevsky AM, Sonntag KC, Isacson O, Kosik KS. 2005. Specific microRNAs modulate ES cell-derived neurogenesis. Stem Cells [Epub ahead of print].

Lagos-Quintana M, Rauhut R, Lendeckel W, Tuschl T. 2001. Identification of novel genes coding for small expressed RNAs. Science 294:853-858.

Lagos-Quintana M, Rauhut R, Yalcin A, Meyer J, Lendeckel W, Tuschl T. 2002. Identification of tissue-specific microRNAs from mouse. Curr Biol 12:735-739.

Lagos-Quintana M, Rauhut R, Meyer J, Borkhardt A, Tuschl T. 2003. New microRNAs from mouse and human. RNA 9:175-179.

Lau NC, Lim LP, Weinstein EG, Bartel DP. 2001. An abundant class of tiny RNAs with probable regulatory roles in Caenorhabditiselegans. Science294:858862.

Lee RC, Ambros V. 2001. An extensive class of small RNAs in Caenorhabditis elegans. Science 294:862-864.

Lee Y, Jeon K, Lee JT, Kim S, Kim VN. 2002. MicroRNA maturation: stepwise processing and subcellular localization. EMBO J 21:4663-4670.

Lee Y, Ahn C, Han J, Choi H, Kim J, Yim J, Lee J, Provost P, Radmark O, Kim S, Kim VN. 2003. The nuclear RNase III Drosha initiates microRNA processing. Nature 425:415-419.

Lim LP, Glasner ME, Yekta S, Burge CB, Bartel DP. 2003a. Vertebrate microRNA genes. Science 299:1540.

Lim LP, Lau NC, Weinstein EG, Abdelhakim A, Yekta S, Rhoades MW, Burge CB, Bartel DP. 2003b. The microRNAs of Caenorhabditis elegans. Genes Dev 17: 991-1008.

Lim LP, Lau NC, Garrett-Engele P, Grimson A, Schelter JM, Castle J, Bartel DP, Linsley PS, Johnson JM. 2005. Microarray analysis shows that some microRNAs downregulate large numbers of target mRNAs. Nature 433:769-773.

Litt M, Kramer P, LaMorticella DM, Murphey W, Lovrien EW, Weleber RG. 1998. Autosomal dominant congenital cataract associated with a missense mutation in the human alpha crystallin gene CRYAA. Hum Mol Genet 7:471-474.

Liu J, Valencia-Sanchez MA, Hannon GJ, Parker R. 2005. MicroRNA-dependent localization of targeted mRNAs to mammalian P-bodies. Nat Cell Biol 7:719723.

Mansfield JH, Harfe BD, Nissen R, Obenauer J, Srineel J, Chaudhuri A, Farzan-Kashani R, Zuker M, Pasquinelli AE, Ruvkun G, Sharp PA, Tabin CJ, McManus MT. 2004. MicroRNA-responsive 'sensor' transgenes uncover Hox-like and other developmentally regulated patterns of vertebrate microRNA expression. Nat Genet 36:1079-1083.

Meister G, Landthaler M, Patkaniowska A, Dorsett Y, Teng G, Tuschl T. 2004. Human Argonaute2 mediates RNA cleavage targeted by miRNAs and siRNAs. Mol Cell 15:185-197.

Mourelatos Z, Dostie J, Paushkin S, Sharma A, Charroux B, Abel L, Rappsil- 
ber J, Mann M, Dreyfuss G. 2002. miRNPs: a novel class of ribonucleoproteins containing numerous microRNAs. Genes Dev 16:720-728.

Nelson PT, Baldwin DA, Kloosterman WP, Kauppinen S, Plasterk RH, Mourelatos Z. 2006. RAKE and LNA-ISH reveal microRNA expression and localization in archival human brain. RNA 12:187-191.

Oberwinkler J, Lis A, Giehl KM, Flockerzi V, Philipp SE. 2005. Alternative splicing switches the divalent cation selectivity of TRPM3channels.JBiolChem280:2254022548.

Petersen CP, Bordeleau ME, Pelletier J, Sharp PA. 2006. Short RNAs repress translation after initiation in mammalian cells. Mol Cell 21:533-542.

Rodriguez A, Griffiths-Jones S, Ashurst JL, Bradley A. 2004. Identification of mammalian microRNA host genes and transcription units. Genome Res 14:19021910.

Rupp RA, Snider L, Weintraub H. 1994. Xenopus embryos regulate the nuclear localization of XMyoD. Genes Dev 8:13111323.

Sewer A, Paul N, Landgraf P, Aravin A, Pfeffer S, Brownstein MJ, Tuschl T, van Nimwegen E, Zavolan M. 2005. Identification of clustered microRNAs using an ab initio prediction method. BMC Bioinformatics 6:267.

Smirnova L, Grafe A, Seiler A, Schumacher S, Nitsch R, Wulczyn FG. 2005. Regulation of miRNA expression during neural cell specification. Eur J Neurosci 21:1469-1477.

Sokol NS, Ambros V. 2005. Mesodermally expressed Drosophila microRNA-1 is regulated by Twist and is required in muscles during larval growth. Genes Dev 19:2343-2354.

Tanzer A, Stadler PF. 2004. Molecular evolution of a microRNA cluster. J Mol Biol 339:327-335.

Turner DL, Weintraub H. 1994. Expression of achaete-scute homolog 3 in Xenopus embryos converts ectodermal cells to a neural fate. Genes Dev 8:1434-1447.

Vo N, Klein ME, Varlamova O, Keller DM, Yamamoto $\mathrm{T}$, Goodman RH, Impey $\mathrm{S}$. 2005. A cAMP-response element binding protein-induced microRNA regulates neuronal morphogenesis. Proc Natl Acad Sci U S A 102:16426-16431.

Wienholds E, Kloosterman WP, Miska E, Alvarez-Saavedra E, Berezikov E, de Bruijn E, Horvitz HR, Kauppinen S, Plasterk RH. 2005. MicroRNA expression in zebrafish embryonic development. Science 309:310-311.
Wood WI, Gitschier J, Lasky LA, Lawn RM. 1985. Base composition-independent hybridization in tetramethylammonium chloride: a method for oligonucleotide screening of highly complex gene libraries. Proc Natl Acad Sci U S A 82: 1585-1588.

Wu L, Belasco JG. 2005. Micro-RNA regulation of the mammalian lin-28 gene during neuronal differentiation of embryonal carcinoma cells. Mol Cell Biol 25: 9198-9208.

Xie X, Lu J, Kulbokas EJ, Golub TR, Mootha V, Lindblad-Toh K, Lander ES, Kellis M. 2005. Systematic discovery of regulatory motifs in human promoters and $3^{\prime}$ UTRs by comparison of several mammals. Nature 434:338-345.

Yekta S, Shih IH, Bartel DP. 2004. MicroRNA-directed cleavage of HOXB8 mRNA. Science 304:594-596.

Yu JY, Taylor J, DeRuiter SL, Vojtek AB, Turner DL. 2003. Simultaneous inhibition of GSK3alpha and GSK3beta using hairpin siRNA expression vectors. Mol Ther 7:228-236.

Zeng Y, Yi R, Cullen BR. 2005. Recognition and cleavage of primary microRNA precursors by the nuclear processing enzyme Drosha. EMBO J 24:138-148. 